\title{
Assuring the Quality of Teacher Education Systems and Its Link to Improvement in Learning Cultures: The Role of the International Reviewer
}

\author{
Gillian L. S. Hilton \\ Institute of Work-based Learning, Middlesex University, UK
}

Copyright $(2016$ by authors, all rights reserved. Authors agree that this article remains permanently open access under the terms of the Creative Commons Attribution License 4.0 International License

\begin{abstract}
This paper addresses the place of the use of international 'experts' in assuring the quality of Teacher Education programmes within Higher Education, in relation to the global agenda of improving standards. The experiences of one such 'expert' are discussed and recommendations made as to the type of person suited to the role. Some issues relating to Teacher Education in the Baltic States of Lithuania and Latvia are addressed, in particular the need for a change in the culture from a focus on teaching to one on learning, the need to embrace, not resist change and the need to respond quickly to an ever changing education agenda. The paper attempts to address some of the difficulties faced by higher education institutions in the Baltic States and also raises the concerns of the international experts, with particular reference to the lack of good data on which to base their conclusions and recommendations. Despite years of membership of the EU change in Eastern European teacher education is not occurring as fast as it needs to and this is where the advice of the 'expert' can be of use.
\end{abstract}

Keywords Quality Assurance, Experts, Change, Teacher Education

\section{Introduction}

We live in a world which appears to grow smaller as its population increases. We are still in many ways however, politically, culturally, economically, and linguistically far apart. We have though a commonality, as shown by interventions of bodies such as the EU and the UN; we are all striving in our own ways to improve our education systems, as this is seen as the way forward to success and improvement in lifestyles. It is not only education in schools and universities that has been under the spotlight, but also vocational education, as we strive for a better informed work force and lifelong learning, as societies accept that knowledge does not stand still and that learners need to be continually refreshed with new skills, knowledge and ideas. Education for all is the watchword, based on the belief that better education leads to better citizenship, promotes increased understanding and harmony within nations and with other countries. However, in an ever increasing competitive economic situation good education is seen as the way to raise the competitiveness of a nation, its GDP and therefore its living standards. All this however, comes at a price and can result in a loss of precious local knowledge, skills and specialisms and the alienation of older generations who can feel marginalised and looked down upon. Therefore these questions need to be asked; what is the effect of the globalisation of quality assurance in education, how does it manifest itself in the provision of education and what is the role of the international reviewer?

\section{Globalisation and Teacher Education}

Globalisation appears to arise from the move towards a global economy, where nations are affected by decisions taken in other parts of the world e.g. the banking crisis of 2008 which, though originating in the USA, resulted in banking collapses in a wide variety of nations with the subsequent loss of employment and regimes of austerity becoming essential. Globalisation is not a new phenomenon; Bates (2002) [1] tells us that the movement of people, ideas and commodities around the world is part of history, but that the rapidity of the process is what is now of concern. Governments appear to be losing control (Carnoy, 1999) [2]. This has been demonstrated by the fight of the UK government in 2013 to extract taxes from large companies based in tax havens such as Luxemburg, whilst earning most of their income elsewhere (Wright, 2013) [3]. As to whether this blurring of cultures and boundaries is a good thing is, as yet uncertain, but the movement appears unstoppable. However, at the same time we have seen a rise in the 
demands for nationhood and separation of identity from many of the world's peoples, which appear to be in direct conflict with the world picture. So we see before us a change in production, the control of money and goods, how work is organised, cultures and even nation states. Indeed the only constant is change.

Education in our world is not able to avoid the competitive nature of globalisation. Nation States want to be those whose education is admired and copied and systems of education are now under intense scrutiny and pressure to produce "the best' in terms of global competitiveness. We now have world rankings of universities, national rankings of schools and many measurements of, so called, education success as far as international comparisons are concerned. Agencies such as OECD, United Nations and the World Bank are closely involved with education reports and comparisons of performances. Added to this, for those in the EU, is the European Commission and its constant supply of suggestions and directives for the way forward in the production of better educated workers and citizens. This global interest and competition in education has led rise to the use of cross border evaluations and quality assurance

This paper discusses the role of quality control or quality assurance (QA) of teacher education and the part played in Higher Education (HE) by international experts. Controlling the quality of education and comparing standards between countries is now a major aspect of the globalisation of education. PISA Timss, Piris etc. are always in the headlines and governments constantly compare the results of their education systems in relation to those achieved by other nations. As PISA reports from OECD appear to demonstrate to us where the successful education systems are, pressure on governments rises (Clifton, 2011) [4]. In the UK (England in particular) this has led to constant changes in curricula, assessment and teacher education programmes. At one point Finland was the admired system in Europe and governments in the UK, in past years, have attempted to emulate the Master's degree status of teachers there (Baker, 2009) [5] Now, Singapore and China are achieving better PISA rankings, (though this may be as a result of a restricted curriculum and excessive coaching) and Finland's results have declined in the international league tables (Taylor, 2013) [6]. Whether these international tests give real insight into the efficacy, or not, of national systems is questionable, but highly popular with government education departments across the world. However, Smithers (2013) [7] suggests that over-reliance on their results should be avoided, as these results are contradictory and as Barker $(2013 ; 12)] 8]$ points out, could lead to 'teaching to the test'. In addition HE is faced with the challenges of spending cuts, higher student fees and a changing demographic. We need, in many parts of Europe, fewer, but better teachers and in the light of this programmes, departments and even universities face closure. At the 2012 World Innovation Summit for Education in Qatar, Geoff Mulgan chief executive for Science Technology and the Arts, raised the possibility of the need for a turnover of universities, with poorer ones being allowed to fail, so that newer and better ones could emerge (Matthews, 2012) [9]. Already national and global university rankings are eagerly contested by some of the leading institutions, whilst others are left to reflect on their poor placing in the lists. However, we have to question as to whether these global league tables are in fact assessing the right areas in their attempt to rank the quality of education provided. Are we looking for and measuring the right things and is everything that we need in an educated person measurable? Are our tests of quality too narrow? This latter is a constant criticism of the PISA tests and has resulted in a move to consider expanding the testing beyond subjects, to include areas such as creativity, the ability to make sound judgements and deal with ambiguity, though some academics think these factors cannot be satisfactorily tested (Stewart, 2013) [10].

In $\mathrm{HE}$ and in teacher education in particular, the growing interest of the European Commission has been noted by the countries in the EU and the rise of the European Association for Quality Assurance in Higher Education (ENQA) has established standards and guidelines for how the QA process is to be carried out. The Bologna Agreement also focussed countries on the move towards closer programme and award structures in the education of teachers and the time spent on initial and further degrees. The movement of countries towards this has been erratic to some extent and has, in some cases, been aided by the use of 'international experts'. These are people from a variety of countries with wide experience of teacher education and an understanding that the ability of teachers to be mobile and work across the EU countries demands a similarity of achievement levels and some way of comparing training standards. In 2006 Eurydice published a report on Quality assurance in teacher education in Europe which described how individual countries were coping with ensuring high quality in their teacher education (Eurydice, 2006) [11]. Hazelkorn (2013) [12] points to the international pressures such as ageing societies, the goal of knowledge transfer and the need to provide value for money, as funding decreases, resulting in pressure on HE institutions to provide high quality programmes with fewer resources. This drive to raise standards and improve quality seems to be underpinned by the desire of governments to persuade their citizens, angry about rising taxes and governments' inability to control costs, that value for money is important in the provision of education, particularly where students are paying ever increasing fees (Hilton, 2003) [13]. As mentioned above, rankings, national and international, are a strong feature of HE now, but there are alternatives, as pointed out by Hazelkorn (2012) [12], such as the European Qualifications Framework (EQF), launched in 2006 and providing a clear level of qualifications across Europe for HE.

\section{Quality Assurance in Teacher Education}

As part of this drive towards improving and equalising 
quality, national institutions have organised and strived to improve the way in which quality is assessed and assured. This has led, in parts of the EU, to the use of the national and also the international assessor of which the author of this paper is one. The English Quality Assurance Agency (QAA, 2011:1) [14] define QA as 'all about guaranteeing the standards and quality of educational provision'. This definition is for the benefit of students, to show them that qualifications from one university are of the same standard as those achieved at other institutions. This is also the intent of the EQF, in that students and employers can be assured that qualifications gained across the EU are compatible. This is of particular interest to teachers, as those trained in EU countries have a right to teach across Europe.

The bravery of countries willing to accept the scrutiny of international experts is to be applauded, as by no means all EU countries have adopted this approach. Cerych (2002) [15] raises questions about the use of foreign education advisors in countries emerging from communist regimes, advising of the need for good understanding of the country visited and a working use of the language. Hilton (2009:1) [16] rejects this negative judgement

it is possible there are some pan-European standards for education that can be applied and that foreign experts, with empathy towards issues of change and development, can provide a more objective viewpoint than insiders.

The language problem however is harder to overcome, as finding foreign experts with a command of eastern European languages, presents considerable difficulties.

Resistance to the quality assurance process in education has, in some areas, been strong. The feelings of English teachers and teacher educators towards Ofsted inspections is well known and Gregory (1991) [17] claimed that a minority of academics strongly resisted the idea that academic work could be subjected to quality control and questioning, as that work is too broad and complex to define. This idea however, was expressed before the advent of the discussion of competences and then standards in teacher education which are now constantly quality assured across Europe.

\section{The Use of the 'Expert'}

In the experience of the author working with the Quality Assurance Agency (QAA) in England, SKVC and aip (The Lithuanian and Latvian equivalents of QAA) the pitfalls of being an 'international expert' are many; these include the widely differing systems, the cultures, the constant changes made by government and EU directives, the need of all concerned to be self-critical, the need for patience and understanding, language barriers and of course the need to complete the work in far too short a time. However, experience tells and, after working in this area for fifteen years, (twelve in the Baltic) and getting to know colleges, universities and people, the writer has gained an understanding of the strengths and weaknesses of different systems. One academic, told me after giving feedback 'you saw everything we hoped to keep hidden'. Therefore for international reviewers to be successful there has to be sympathy and understanding, linked to a firmness of intent and a willingness to give sometimes difficult news to hard working and committed staff. Changing the education culture has been the intent of the teams I have led over the years, from one which is teacher dominated, to one based on learning, where student need drives the programme. All Europe needs good teachers if we are to succeed in the global race for excellence and using techniques rooted in the past is not acceptable The McKinsey Report (Barber \& Mourshed, 2007) [18] on the world's best performing school systems concluded, that it is the quality of the teachers produced in a country that determines the success of its education system; teacher education therefore has to be of the highest quality There is an accepted link between success in education and economic performance and with concerns in the EU over high unemployment rates and stagnating economies, it is understandable that the move towards greater convergence of European education systems is gaining apace, as this is seen as a way of alleviating unemployment and encouraging labour mobility.

\section{The Need for Change}

Change is ever with us and has to be embraced not resisted, even when on some occasions, it is driven by questionable ideologies which have to be overcome. Fullan (2005) [19] acknowledges that change is difficult and challenging, as it often asks us to step into the unknown, where we feel vulnerable and exposed. However, to move forward and improve quality we have to embrace not reject change. It was noticeable to the visiting 'experts' where change was accepted or even welcomed and where it was strongly resisted. It was interesting to observe the difference in approaches by Baltic States and their HEIs to EU directives in areas such as learning outcomes and mentoring of students on placement. To someone who is used to very strict control from government, the somewhat lassie-faire attitude of some academics, and even government officials and some HEIs' slow response to change agendas, in the Baltic States proved to be a frustrating experience. 'We haven't got round to it yet', 'the Senate has not discussed it' are excuses given to this author and her teams for not implementing government and EU directives in place for six years. Maybe the interpretation of democracy has gone a little too far, as has a somewhat easy relationship between HEIs and those, in some countries, who are responsible for quality assurance.

One of the greatest battles faced by Lithuania and Latvia in the last few years has been the decrease in student numbers and children needing to be taught. This is one area where the external reviewer, with wide experience of similar problems, can be of real help to HEIs and government departments. Burying one's head in the sand is not 
acceptable, the problem has to be approached or costs will become unsustainable. However, the visiting reviewers were presented on our visits with very poor data. In order to ascertain the place of a programme in the country's provision some data sets are essential. Namely, staff/student ratios for each programme, income for the programme, numbers of students in each year with yearly drop out and failure rates, employment rates of students in the vocation they trained for and above all national and local needs for that particular specialism. Without this specific data it is impossible to judge if there is an actual need for the programme in the country. For academics anxious to continue in employment there have been disturbing trends, including mass emigration, a drop in the need for school places and unfortunately far too many unqualified teachers working in schools. All these, with salary cuts and reducing government funding, are threatening the lives of those in HEIs. Of the dedication of staff there is no question, but there were, in comparison to many areas of Europe, some serious concerns for the reviewers.

\section{The Research}

These observations are the results of twelve years of leading review teams, preparing reports from site visits and discussions with staff, observations, perusal of self-evaluation documents and student work, experts reports on standards, HEI and agencies' responses to those reports and discussions with agency staff and Ministries and national seminars led by this author.

Staff training students to be teachers, were too oriented towards theory and not practice. Recent changes had brought degree programmes into line with the Bologna agreement with the three/four year cycle for Bachelor's programmes and the idea of each year containing school practice. However, this in many cases was not real practice, but the collecting of information or conducting research. In many programmes there needed to be a mental attitude change, with much more emphasis being placed on school practice and those who are responsible for its assessment better trained in how to assess teaching and learning outcomes. Assessment in general was too lax and easy, too much overall, but not of a high enough standard; we needed to see some students fail! Producing good teachers meant that the best professors, oriented towards school work were required, who themselves had trained to teach and who had wide experience of school teaching which was not the case in most programmes. The ideas of benchmarking for programmes and the use of learning outcomes from the original programme planning, through to individual modules and the assessment of a student, required adopting but this was being, in many cases, ignored. Class sizes were too small, lacking validity and minimum class sizes needed to be established before a programme could commence. Interviews to select all those entering training programmes, not merely those who receive state funding was recommended by the teams or at least, potential students should be assessed on their suitability for teaching. A questionnaire used in Lithuania, designed to judge motivation to be a teacher was far too easy. 'Experts' believed that students should have at least spent some time in a school before applying for the programmes. The high drop-out rates in year one underlined the need for better candidate selection. Training for mentors was not standard practice, as 'experience' as a teacher was seen as sufficient preparation for the role, unless EU money was forthcoming for training. In reality there was too much reliance on EU funding, possibly a throwback to rigid Soviet control.

These points and many others have become constant themes in the general reports I have been writing for twelve years. This is not to say that the international experts want everyone to be the same. The Baltic States have a great history of music and craft education for example, areas sadly lost in many EU countries, but the standards of teacher education need to be consistent when compared with other countries and also between HEIs internally. There was too much variation in standards between HEIs as regards equipment, permanent staff and programmes offered. However, a continuing theme was a teaching, as opposed to a learning culture in many programmes on offer. To some extent, this was caused by a lack of government control over HEIs, who seemed able to invent new programmes of similar natures, to ones that had been recently closed and the lack of a robust external examiner system common in other countries. The use of national and local data showing the needs for particular teacher specialisms was not used to govern what programmes were offered and a business case was not always presented. This is a harsh necessity in the present economic climate. In Latvia for example my teams were astonished when one HEI proudly told us that few of their graduates worked in the country but had jobs in Germany, Scandinavia and the USA. Their reasoning was that students paid for their education. However, it seemed that government financial support for the university itself and its staff was not considered. If I were a local tax payer I would have questioned why a public university was being sustained, by national funds, to provide teachers for other countries.

In all these areas the international expert can help, in working with academics in the HEIs to help them adjust their thinking and practices. For example, giving guidance on how to word Intended Learning Outcomes, as per the EU Dublin Descriptors. These need clear differentiation between the different year levels and the different qualifications, at Bachelor's Master's and Doctorate levels. As many of us have struggled through the same process we understand the pitfalls and difficulties faced and in many cases wish we had received guidance from 'experts' before our own attempts to benchmark, or produce intended learning outcomes linked throughout a programme to its assessment. Of course, not all our suggestions are possible, but ones, such as the adoption of national external examiners between HEIs, would aid a rise in quality and assure that at least minimum standards are 
reached nationally. However, for these kinds of recommendations to be accepted a further hurdle, that is, government determination to improve and assure quality, has to be in place. One tended to observe a lack of real determination on the part of those governments to insist on quality raising and a tendency to bow to the pressure of HEIs and their constant cries about poor funding. Better data, fewer programmes, even possibly fewer HEIs, would have helped to improve quality, but those decisions take courage. The external expert can advise but cannot ensure implementation, even when Ministers appear to agree with points strongly made.

What are the requirements for an international expert? Here is a list of some but by no means all qualities needed for the role noted as a result of numerous site visits with different groups of experts coming from a wide variety of European countries. It must be said that not all 'experts' fulfilled the requirements.

Honesty; integrity; ability to withstand pressure; observant; a good listener; able to note what is not said as well as what is; persistence to pursue a point to obtain clarity; ability to work very quickly for long hours; patience; empathy; be prepared to encourage as well as to blame; be able to explain things well and ensure all understand; be able to demand data which is of an acceptable standard. Above all to be willing to work for very little money for long hours at top speed!

For the team leader one needs control over the panel and an ability to take all opinions into account, to be able to resist pressure from individuals, academies and governments; to dispassionately measure programmes against the set standards, keeping an eye on what is acceptable across Europe; to be prepared to be very unpopular if the outcomes are disliked and to be aware of and alert to interference from those who have vested interests; to be ready to face the consequent questioning from the media, the $\mathrm{EU}$ or other funders if the results are not what are wanted.

Therefore it is a good and brave enterprise undertaken by the Baltic governments in using foreign experts to help in QA. We know that the Bologna reforms have brought serious challenges to HEIs and the academics who work in them (O'Dowd, 2009) [20]. One must not underestimate the problems faced by staff in HEIs who have for decades been dealing with shifting demands and ever changing practices. As Keeling (2006:214) [21] points out, these reforms have demanded a great deal from academics and 'often painful restructuring of working practices and in many cases a loss of professional autonomy in both teaching and research'. However, having been subject to this close scrutiny and played a part in international reviews I must agree with Coles (2013: 46) [22] who argues that accountability is

...not a necessary evil but a good thing. We are at our best when we are properly accountable for our actions, when there is proper scrutiny of the things we have done and we bear the consequences.

Coles (2013) [22] points out that the risk in our QA is one of too narrow a focus, so that we begin to consider targets and not aims and outcomes. The more accountability measures there are in place, the more we will be aims driven. It would be good if international bodies, governments and reviewers could keep this closely in mind. All one can ask is that the reviewer is widely experienced and has empathy because we can all learn from the opinions of others.

\section{Conclusions}

So are international experts a good idea? The answer has to be yes, as in this increasingly global world we have to see some clear commonalities and a striving towards high quality and how that is assessed. However, to be effective one has to be listened to and it is true to say that the 'experts' can become very frustrated if, after years of saying the same things, the same problems arise during subsequent visits. I have been told that not only my teams but others, in different subject areas have come to similar conclusions, yet some things have not been changed. To some extent this is of course one of the difficulties of democracy as opposed to autocracy; the fact that successive governments always try to go against what has happened before, plus of course 'experts' are not always right. The answer lies really with the HEIs and their questionable determination to lead the way to change; are they more intent on keeping the old 'safe' Soviet system where no-one retires and no-one questions? Maybe one of the things the 'experts' should closely examine is the quality of the leadership of institutions, though that is the role of the institutional reviews of Higher Education Institution which have been happening already. However, at present it is unclear if many HEIs and the programmes within them are as yet ready to be left to internal QA, without the help of those who can delve more deeply into individual programmes. We need to proceed with caution to get things right. To re-iterate as an international 'expert' one must not be afraid of being unpopular! However, it is a worthwhile and enjoyable if sometimes frustrating role. The young people in these countries want change; they are bright, hard-working and eager to improve their lives. As a result of their dissatisfaction with the status quo, the countries are losing many of their most promising young people to emigration, to countries where they see more opportunity. One Latvian met in London, told me she had started a programme at a university in Latvia but gave up in despair as 'the professors are so out of touch with the modern world'. She has since started a degree course in London is very happy and totally engaged. Change cannot come too quickly.

\section{REFERENCES}

[1] Bates, R, (2002) Administering the global trap: the roles of educational leaders, Educational Management, and Administration, 30, 2, 139-156. 
[2] Carnoy M. (1999) Globalisation and Educational Reform What Planners Need to Know, UNESCO, Paris.

[3] Wright, O. (2013) 'Amazon's corporation tax bill less than grants', Times Higher Education, 16. 05. 2013.

[4] Clifton, J. (2011) International comparisons can be instructive if used properly- but on this too England is lagging behind, Times Educational Supplement, 15.07.2011.

[5] Baker, M. (2008) Masters of the classroom? BBC news/education http://news.bbc.co.uk/1/hi/education/8121574.stm (Accessed $07.11 .2015)$

[6] Taylor, A. (2013) Finland used to have the best education system in the world - what happened? Business Insider Education http://www.businessinsider.com/why-finland-fell-in-the-pisa -rankings-2013-12?IR=T (Accessed 07.11.2015).

[7] Smithers, A. (2013) Confusion in the ranks: how good are England's schools? Report for the Sutton Trust, http://www.buckingham.ac.uk/wp-content/uploads/2013/01/ Confusion-in-the-Ranks.pdf (Accessed 25.07.2013).

[8] Barker, I. (2013) 'See-saw rankings on shaky ground', Times Educational Supplement, 01. 02. 2013.

[9] Matthews, D. (2012) 'The price of quality and innovation is failure’ Times Higher Education, 22. 11. 2012.

[10] Stewart, W. (2013) 'Pisa's tests could get curiouser and curiouser' Times Higher Education, 21. 06. 2013.

[11] Eurydice (2006) Quality Assurance in Teacher Education in Europe, Brussels, Eurydice/European Commission.

[12] Hazelkorn, E. (2012) European "transparency instruments": Driving the Modernisation of European Higher Education, in P. Scott, A.. Curaj, L. Vlăsceanu, L. Wilson, (eds.), European Higher Education at the crossroads: between the Bologna
Process and national reforms, Volume 1, Dordrecht: Springer.

[13] Hilton (2003) 'Is the tail wagging the dog? An exploration of quality assurance procedures in Higher Education in England', Association of Teacher Educators in Europe Annual Conference Malta, August, 2003.

[14] QAA (2011) What is quality assurance? Gloucester, QAA.

[15] Cerych, I. (2002) 'Higher Education Reform in the Czech Republic: A Personal Testimony Regarding the Impact of Foreign Advisers', Higher Education in Europe, 27, 1-2, pp111-121.

[16] Hilton, G. (2009) 'The Quality of Teacher Education in new EU member states; the role of the 'foreign expert', Paper given at the Bulgarian Comparative Education Society Conference Sofia, Bulgaria May 2009.

[17] Gregory, K. (1991) 'Assessing departmental academic performance a model for a UK University, Higher Education Review, 23, 2, pp44-61

[18] Barber, M. Mourshed, M. (2007) how the world's best performing school systems come out on top, London/USA, McKinsey Corporation

[19] Fullan, M. (2005) Leadership and Sustainability, Thousand Oaks, California, Corwin Press.

[20] O’Dowd. M. (2009) Supranational Regimes and their influence on education, Occasional Papers in Education and Lifelong Learning 3, pp1-2, 6-38.

[21] Keeling, R. (2006) 'The Bologna Process and the Lisbon Research Agenda: the European Commission's expanding role in higher education discourse' European Journal of Education, 41, 2, pp203-223.

[22] Coles, J. (2013) 'Accountability works: Let's have more of it', Times Higher Education, 11. 01. 2013. 